
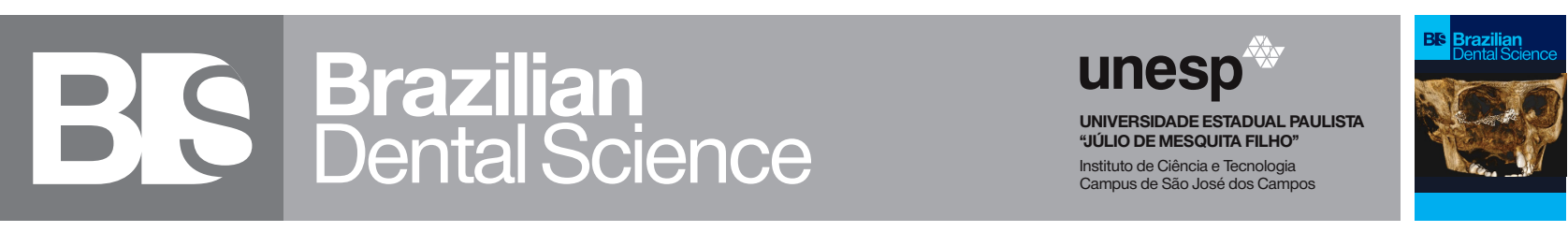

\title{
Quality of life in a smoking cessation program: lifestyle, anxiety, and depression
}

\author{
Qualidade de vida em um programa de cessação do tabagismo: estilo de vida, ansiedade e depressão
}

Daniela Junqueira de FARIA ${ }^{1}$, Adriana Ávila de ALMEIDA ${ }^{1}$, Igor Boaventura da SILVA ${ }^{1}$, Ivan BALDUCCI ${ }^{2}$, Celina Faig Lima CARTA ${ }^{1}$, Denise NICODEMO ${ }^{2}$, Janete Dias ALMEIDA ${ }^{1}$

1 - Department of Biosciences and Oral Diagnosis - São Paulo State University (Unesp) - Institute of Science and Technology - São José dos Campos - SP - Brazil.

2 - Department of Social Science and Pediatric Dentistry - São Paulo State University (Unesp) - Institute of Science and Technology - São José dos Campos - São Paulo - Brazil.

\begin{abstract}
Objective: Tobacco dependence is quite variable among individuals because it includes many aspects such as psychological, emotional, behavioral, and cultural perspectives. This study aimed to evaluate the social and emotional issues of patients in a smoking cessation program through the generic and specific quality of life questionnaires. Material and Methods: Two generic questionnaires (SF36 and Fantastic Lifestyle) and two specific (SRQ-20 for depression and STAI s/t for levels of state and anxiety trait) were applied at the first meeting and after three months of treatment. Data were statistically analyzed by the Pearson correlation coefficient (significance level of 5\%). Results: In total, 15 participants (10 men, 5 women), with mean age of 60 and 56, respectively. The mean of the smoking intake was $65.88 \pm 34.37$ for men and $35.66 \pm 11.17$ for women. SRQ20 and STAI s/t indicated that poor improvement in depression and anxiety was related to relapse; SF36 questionnaire indicated improvement in the domains of physical aspect limit, pain, social and emotional aspects; Fantastic Lifestyle indicated improvement according to its scale, being in a first moment "Regular" (53 points), and later, "Good" (55.67 points). Conclusion: In conclusion, smoking cessation treatment is correlated to the decrease in anxiety and depression levels and improvement of the general quality of life.
\end{abstract}

\section{KEYWORDS}

Quality of life; Smoking cessation; Life style; Anxiety; Depression.

\section{RESUIMO}

Objetivo: A dependência do tabaco é bastante variável entre os indivíduos porque inclui muitos aspectos, como perspectivas psicológicas, emocionais, comportamentais e culturais. Este estudo teve como objetivo avaliar as questões sociais e emocionais de pacientes em um programa de cessação tabagágica por meio de questionários genéricos e específicos de qualidade de vida. Material e Métodos: Dois questionários genéricos (SF36 e Estilo de Vida Fantástico) e dois específicos (SRQ-20 para depressão e IDATE s/t para níveis de estado e traço de ansiedade) foram aplicados no primeiro encontro e após três meses de tratamento. Os dados foram analisados estatisticamente pelo coeficiente de correlação de Pearson (nível de significância de 5\%). Resultados: No total, 15 participantes (10 homens, 5 mulheres), com média de idade de 60 e 56 anos, respectivamente. A média do consumo tabágico foi de $65,88 \pm 34,37$ para homens e 35,66 $\pm 11,17$ para mulheres. SRQ20 e IDATE $s / t$ indicaram que a fraca melhora na depressão e ansiedade estava relacionada à recaída; o questionário SF36 indicou melhora nos domínios limite do aspecto físico, dor, aspectos sociais e emocionais; Estilo de Vida Fantástico indicou melhora de acordo com sua escala, sendo em um primeiro momento "Regular" (53 pontos), e posteriormente, "Bom" (55.67 pontos). Conclusão: Em conclusão, o tratamento para cessação do tabagismo está correlacionado à diminuição dos níveis de ansiedade e depressão e à melhora da qualidade de vida geral.

\section{PALAVRAS-CHAVE}

Qualidade de vida; Abandono do Uso de Tabaco; Estilo de vida; Ansiedade; Depressão. 


\section{INTRODUCTION}

A ccording to the World Health Organization (WHO), tobacco use is the leading preventable cause of death worldwide, killing more than seven million people a year [1]. Smoking is one of the risk factors for chronic noncommunicable diseases (CNCD) such as cancer, cardiovascular and pulmonary diseases, which account for 40 million deaths annually, equivalent to $70 \%$ of all deaths in the entire world. Besides, it is also a risk factor for diabetes, duodenal and gastric ulcers, and still has a strong association with fire-related injuries due to hot cigarette smoke, and the trauma of constant contact of the burning cigarette on the lip [1-5].

Smoking is considered an additive disease due to the effect of nicotine on the brain reward system. When inhaled, nicotine is absorbed through the lungs. It falls into the bloodstream where it can reach the brain for 7 to 9 seconds, releasing various neurotransmitters that induce pleasure and reduce stress and anxiety [3]. Smoking improves the concentration, mood, and performance of specific tasks [2]. The cessation of nicotine use may lead to withdrawal symptoms, and cigarette smoking is often used to promote the relief of these symptoms and a return to a sense of well-being [6]. Among the withdrawal symptoms, it can be found irritability, depressed mood, agitation, and anxiety [7].

Diseases related to tobacco use arise as a result of exposure to toxins found in smoke. The nicotine addiction causes the smoker to inhale more than 7,000 substances such as carbon monoxide, ammonia, ketones, formaldehyde, and 43 carcinogenic substances, mainly: arsenic, nickel, benzopyrene, cadmium, lead, pesticide residues and radioactive substances that cause various diseases, including cancer $[2,3,8]$.

Quality of life (QoL) has becomean important outcome measure in all-medical specialties in both clinical and research settings. Large health organizations, such as the WHO, have suggested that QoL should be incorporated as an outcome measure in clinical care $[9,10]$. Therefore, the analysis of the results of QoL questionnaires may be an aid to a better understanding of the effect of smoking treatment on specific and general aspects of the participants' physical and mental health.

Smoking cessation treatment should be provided to every smoker as an opportunity to stop smoking with the help of specialized health professionals, once this support can at least double the chances of a successful attempt. As important as medical appointments, the dental consultation is an opportune moment to address the issue, since smoking is a risk factor for several systemic, and oral diseases (such as periodontitis and oral cancer) [11-14]. Due to this reason, a program for the study on tobacco use cessation was created at São Paulo State University (Unesp), Institute of Science and Technology (ICT), São José dos Campos, SP, Brazil. This program counted on medical and dental consultation and was directed for smoking patients in dental treatment at the Institution.

The aim of this study was to evaluate, in a comparative way, the social and emotional aspects of patients in a smoking cessation program through generic QoL questionnaires, SF-36, Fantastic Lifestyle; and two specifics, SRQ-20 was used for depression, and STAI s/t for levels of state and anxiety trait.

\section{MATERIAL AND METHODS}

This research was approved by the Research Ethics Committee of the ICT-UNESP under the CAE number: 42387315.0.0000.0077. All participants agreed to participate in the study and signed the Informed Consent Term (ICT).

This is a retrospective, comparative study to evaluate the QoL of smokers before and after smoking cessation treatment. Among the entire group of smokers treated (64 participants) admitted for smoking cessation treatment in the ICT-UNESP in the period from August/2016 to June/2017, only fifteen were eligible for the follow-up study. They were analyzed for QoL before treatment (1st application) and after 3 months (2nd application). Forty-nine participants were excluded because they have answered only the first Qol.

A multidisciplinary team composed 
of a pulmonologist specialist in smoking cessation treatment performed the treatment. All participants underwent a clinical and oral evaluation, received educational support material. When necessary, supportive medication was prescribed, which included nicotine replacement therapy (NRT), composed of adhesive patch and nicotine sublingual tablets. Cognitive and behavioral therapy (CBT) techniques were offered for all participants with the intention of changing habits and prevent relapse.

In addition to general demographic data, questions were asked about the smoking profile that included: the age when the participant starts using tobacco regularly, amount and duration of tobacco use, type of tobacco used, previous cessation attempts, triggers, and initial motivational phase.

An evaluation of the nicotine dependence was carried out through the Fagerström Test for Cigarette Dependence (FTCD), which consists of questions regarding tobacco consumption. The final score predicts the degree of physical dependence on cigarette use and allows classification into five categories: very low (0 to 2 points), low (3 to 4 points), moderate (5 points), high (6 to 7 points) and very high ( 8 to 10 points) $[16,17]$.

The quantification of the smoking load was done with the calculation of packs/year, defined as the number of cigarettes consumed per day divided by 20 and multiplied by the years of consumption [9].

The evaluation of the motivational stage was based on the Transtheoretical Model of Prochaska and DiClemente, which is composed of five phases: pre-contemplation, contemplation, prepared for action, action, and maintenance [18].

The QoL evaluation was performed through the application of four questionnaires, standardized and validated for the Brazilian population. The SF-36 and the questionnaire Fantastic Lifestyle were used for assessment of the QoL and lifestyle, respectively, and generically. For the evaluation of the specific aspects of QoL, SRQ-20 was used for depression, and STAI s/t for levels of state and anxiety trait in this order.

\subsection{Brazilian version of the SF-36}

The Brazilian version of the SF-36 questionnaire was used to assess reported generic health. The generic QoL assessment questionnaire (SF-36) emphasizes the individual's perception of their health in the last four weeks considering eight domains divided into two major groups or aspects: physical and mental. In the physical, the following domains are evaluated: functional capacity (FC), physical aspects (PA), pain (PN), and general health status (GHS). Mental health $(\mathrm{MH})$, emotional aspects (AE), social aspects (SA), and vitality (VIT) are evaluated in the mental domain. Following the evaluation criteria of the questionnaire, scores are scored from 0 to 100, that is, from the worst to the best health status [19].

\subsection{Fantastic Lifestyle}

The Fantastic Lifestyle questionnaire (FLQ) is an instrument that considers the behavior of individuals in the last month, allowing an association between lifestyle and health. "Fantastic" comes from the acronym FANTASTIC representing the initial letters of the domains that evaluated in the English language. It has 25 questions or items that are distributed in the nine domains: 1 . family and friends; 2 . physical activity; 3. nutrition; 4. cigarettes and drugs; 5. alcohol; 6. sleep, seat belt, stress, and safe sex; 7. type of behavior; 8. introspection; 9. work. The sum of all the points allows to arrive at a total score that classifies the individuals into five categories that are: "Excellent" (85 to 100 points), "Very good" (70 to 84 points), "Good" (55 to 69 points), "Regular" (35 to 54 points) and "Need to improve" (0 to 34 points) [20].

\subsection{SRQ-20}

SRQ-20, an instrument developed for the screening of psychic and emotional disorders in primary care services to detect non-psychotic diseases. It consists of 20 affirmations with Yes or No option for each one. The score follows the standardization of the questionnaire, in which the sum of the number of answers given to 'Yes' is 
performed, and the result greater than or equal to 8 represents a state of depression [21].

\section{$2.4 S T A I s / t$}

The STAI s/t was used to measure anxiety, being a scale of self-report that depends on the conscious reflection of the subject in the process of evaluation of his/her state of anxiety, as well as the characteristics of his/her personality. The objective is to measure Anxiety-State (transient emotional state) and Anxiety-Trait (a tendency of how to react to situations). The test consists of two anxiety scales, each with 20 items. Scores from 20 to 34 points indicate low anxiety, from 35 to 49 points show moderate anxiety, from 50 to 64 points show high anxiety and from 65 to 80 points show very high anxiety [22-24].

\subsection{Statistical Analysis}

Nonparametric tests were chosen for the patient-reported outcome. The data were treated in a descriptive and inferential manner. The categorical variables were presented in terms of absolute values and percentages, and the numeric variables in terms of means and standard deviations. Wilcoxon-Mann-Whitney tests were used to compare sample characteristics between the 15 participants who answered the QoL before treatment (1st application) and after 3 months (2nd application) and the remain 49 participants who replied only the first QoL. The Pearson correlation was used to determine the correlation between the QoL domains and the numerical variables of the study. For all statistical tests, the significance level $\mathrm{p}<0.05$ was used, and the statistical software GraphPad Prism 6 was used.

\section{RESULTS}

Out of 64 eligible patients, 15 answered the follow-up study, giving a response rate of $23.4 \%$. The characteristics of the demographic profile and tobacco consumption are described in Table I. The majority were men (age 37-81 years) and women (age 52-64 years).
Table I - Descriptive statistics of wear results (Mean values \pm SDs) for both groups at different evaluation time

\begin{tabular}{|c|c|}
\hline Variables & Participants $(n=15)$ \\
\hline \multicolumn{2}{|l|}{ Gender } \\
\hline Men & 10 \\
\hline Women & 5 \\
\hline Age/years (Mean士SD) & $58.93 \pm 10.24$ \\
\hline Men & $60.30 \pm 11.97$ \\
\hline Women & $56.20 \pm 5.50$ \\
\hline Start tobacco use, years (Mean \pm SD) & $14.93 \pm 3.77$ \\
\hline Men & $14.5 \pm 4.17$ \\
\hline Women & $15.8 \pm 3.03$ \\
\hline Usage time, years (Mean \pm SD) & $44 \pm 9.91$ \\
\hline Men & $45.8 \pm 11.59$ \\
\hline Women & $40.4 \pm 4.6$ \\
\hline $\begin{array}{l}\text { Amount of industrial smoked cigarettes/day } \\
\text { (Mean } \pm \text { SD) }\end{array}$ & $24 \pm 9.69$ \\
\hline Men & $28.13 \pm 9.98$ \\
\hline Women & $17.40 \pm 4.34$ \\
\hline Smoking load, packs/year (Mean士SD) & $54.25 \pm 31.06$ \\
\hline Men & $65.88 \pm 34.37$ \\
\hline Women & $35.66 \pm 11.17$ \\
\hline Cessation of tobacco use & 9 individuals \\
\hline Men & 6 \\
\hline Women & 3 \\
\hline \multicolumn{2}{|l|}{ Relapse } \\
\hline Men & 5 \\
\hline Women & 0 \\
\hline FTCD, points (Mean $\pm S D)$ & $5.46 \pm 2.44$ \\
\hline Men & $5.88 \pm 2.42$ \\
\hline Low to Moderate $(0-5)$ & 4 \\
\hline High to very high $(6-10)$ & 4 \\
\hline Women & $4.80 \pm 2.59$ \\
\hline Low to Moderate $(0-5)$ & 3 \\
\hline High to very high $(6-10)$ & 2 \\
\hline Industrialized cigarette / patients & 13 \\
\hline Straw cigarette / patients & 2 \\
\hline \multicolumn{2}{|l|}{ Motivational phase, patients } \\
\hline \multicolumn{2}{|l|}{ Pre-contemplation } \\
\hline Contemplation & 4 \\
\hline Readiness for action & 11 \\
\hline
\end{tabular}


For generic health, the analysis of SF-36 showed that only the indicators of the physical aspects, pain, social aspects, and emotional aspects had improved, but there were no significant differences in SF-36 scores between the 1st application and 2nd application measurements (Table II). Physical aspects were the domain showing the most significant change, with a positive change of 13.66 points.

Table II - Description of mean values obtained for each domain evaluated in the first and second questionnaire assessments.

\begin{tabular}{|c|c|c|c|}
\hline Questionnaire & & Participant scores & \\
\hline SF36 & $1^{\text {st }}$ assessment & $2^{\text {nd }}$ assessment & \\
\hline Domain & $($ Mean \pm SD) & $($ Mean $\pm S D)$ & p.value ${ }^{\star}$ \\
\hline FC & $67.33 \pm 24.70$ & $67.33 \pm 24.19$ & 0.8555 \\
\hline LPA & $54.67 \pm 46.73$ & $68.33 \pm 40.61$ & 0.2500 \\
\hline PAIN & $66.60 \pm 21.57$ & $58.87 \pm 27.54$ & 0.1064 \\
\hline SGH & $54.30 \pm 22.05$ & $54.73 \pm 20.96$ & 0.6580 \\
\hline VIT & $58 \pm 19.62$ & $59.93 \pm 21.76$ & 0.2891 \\
\hline SA & $75 \pm 23.62$ & $81.67 \pm 26.67$ & 0.3359 \\
\hline EA & $66.66 \pm 37.80$ & $77.72 \pm 34.90$ & 0.1094 \\
\hline MH & $65.87 \pm 23.56$ & $65.33 \pm 30$ & 0.6929 \\
\hline \multicolumn{4}{|l|}{ SRQ20 } \\
\hline $0-20$ & $6.93 \pm 5.35$ & $5.13 \pm 5.05$ & 0.0879 \\
\hline \multicolumn{4}{|l|}{ STAI } \\
\hline STAl status & $51.33 \pm 9.76$ & $56.33 \pm 5.56$ & 0.5509 \\
\hline STAl trace & $55.53 \pm 16.20$ & $54.73 \pm 6.21$ & 0.1559 \\
\hline Fantastic Lifestyle & $53.00 \pm 9.51$ & $55.67 \pm 12.48$ & 0.1559 \\
\hline
\end{tabular}

The analysis of the FLQ showed that there was an increase in the mean of the "regular" to "good" lifestyle indicator, but without statistical significance (Table II).

The SRQ-20 analysis showed that there was a small decrease in the mean concerning the indicator of depression, but without statistical significance (Table II). The description of the amount and percentage of how many women and men scored higher than or equal to 8 (Table III).
Table III - Description of amount and percentage of how many women and men scored higher than or equal to 8.

\begin{tabular}{c|cccr|} 
Questionnaire & \multicolumn{4}{c|}{ Participant scores } \\
\hline \multirow{2}{*}{ SF36 } & \multicolumn{1}{|c|}{ st $^{\text {assessment }}$} & \multicolumn{2}{|c|}{$\mathbf{2}^{\text {nd }}$ assessment } \\
\hline Women & $\mathbf{n}$ & $\%$ & $\mathbf{n}$ & $\%$ \\
\hline Men & 2 & 40 & 1 & 20 \\
\hline & 4 & 40 & 3 & 30 \\
\hline
\end{tabular}

The analysis of STAI s/t showed that there was an increase in the mean in the state anxiety indicator and a decrease in the mean in the trace anxiety indicator, but without statistical significance

The first evaluation of the STAI questionnaire showed no correlation between the trace and state aspects ( $r=0.201, p=0.468)$, as well as SRQ20 and state $(\mathrm{r}=-0.087, \mathrm{p}=0.724)$ and SRQ20 $(\mathrm{r}$ $=0.209, p=0.451)$. In the second evaluation of the STAI questionnaire, no significant results were also found when the correlations between trace and state $(r=-0.460, p=0.081)$, SRQ20 and state $(\mathrm{r}=-0.367, \mathrm{p}=0.177)$ were evaluated. However, a significant negative correlation was observed for SRQ20 and trait $(r=-0.559 ; \mathrm{p}=0.030)$.

\section{DISCUSSION}

The main findings of this study showed that the physical, social, and emotional aspects indicators, as well as pain and lifestyle domains, had improved after the smoking cessation treatment.

Smoking is the leading cause of preventable diseases in the world, with well-established effects on the physical and emotional state of smokers $[1,3,4,9]$. Therefore, the evaluation and study of aspects that can measure QoL have become an important outcome measure for understanding the impacts of smoking and smoking cessation for the patient [25].

The success of smoking cessation treatment strategies is related to the motivation for an attempt to quit smoking [18]. Bethea et al. (2015) observed that children, family, and financial issues could be effective motivations for the cessation 
of smoking [26]. In dentistry, during or after treatment, aesthetics aspects may contribute as a motivation for smoking cessation treatment.

It was observed that nine individuals (55\%) were able to quit smoking, while others decreased their cigarette consumption. However, 5 of the 9 patients relapsed and returned to usual consumption. Bethea et al. (2015) described this situation, demonstrating that smokers underestimate their own risk believing in the benefits of cigarette smoking as "stress relief" [26].

The literature shows that the earlier the onset of tobacco use, the greater the chances of the smoker becoming dependent. The continuous presence of nicotine in the body can be responsible for the tolerance process that increases the needed doses of nicotine for maintaining the same level of satisfaction achieved at the beginning [2,3].

According to data from WHO 2017, in Brazil, the prevalence of people aged 15 years or older who smoke is $30.6 \%$ [1]. In our sample, the mean age of onset of tobacco use was $14.93 \pm 3.77$. We find similar numbers to the world literature that shows that $90 \%$ of smokers start smoking before age 19 [4].

Smoking is a chronic and recurrent disease in which relapses and many cessation attempts are common until definitive cessation use [8,9]. In the present study, $11(73.33 \%)$ had already made at least one attempt. The FTCD was chosen because it is a widely used questionnaire worldwide that assesses the degree of nicotine addiction in a quick, simple, non-invasive, and low-cost manner $[16,17,27,28]$. The FTCD guides the professional in the choice and prescription of the drugs for the treatment of smoking, taking into account the degree of physical dependence [29-31]. In the present study, $40 \%$ of the patients had high or very high nicotinic dependence. This fact may also justify the number of individuals who relapsed during treatment.

The 'smoking load' is defined as the individual's lifelong exposure to smoking [9]. The consumption of 20 or more cigarettes per day occurs in $2.8 \%$ of the Brazilian population according to data from VIGITEL [32], which is in agreement with our study, where most participants smoke 20 or more cigarettes/day.

The evaluation of cognitive and behavioral components is used as a helping tool to create and direct the action plan for cessation. We incorporate the motivational stage of change in our smoking profile as a guide for the intensive intervention [18]. Each stage has particular aspects of being accessed. As an example, a person who is at the pre-contemplative stage does not see a quit attempt as necessary because the smoking habit as a risk behavior is not seen as a problem at that time. In our sample, most of the participants said that they were ready to make a quit attempt at the first meeting, also called 'preparation.' However, as an addictive disorder, tobacco use not rarely needs many quit attempts until the definitive abstinence, which may justify the number of relapses found in our study.

The most common causes of relapse, triggers, frustrations, and automatic mechanisms for smoking and gratification must be evaluated and discussed. The situations of ambivalence also need to be addressed since they can be responsible for barriers to smoking cessation success [33].

Nicotine dependence due to tobacco use also includes psychological or emotional components and behavioral or routines [8,9]. Triggers are behavior patterns, situations, places, people, and/ or emotions that lead smokers to automatically light a cigarette without consciousness of this process or not necessarily related to the lack of nicotine in the body [9]. Some triggers are regular daily situations (e.g., anxiety, sadness, joy, alcohol use, work, coffee) and not recognized as an automatic behavioral repetition. The simple modification of these repeated actions can contribute to a smaller amount of cigarettes smoked at the end of the day. Anxiety and coffee were the primary triggers cited by 93.33 and $80 \%$ of participants, respectively.

All patients who achieved abstinence used nicotine replacement therapy (NRT) (patch, gum and lozenge). The NRT can help the cognitive or emotional disturbs, once the abrupt intake of nicotine use may exacerbate difficulty concentrating and mood changes such 
as irritability and anxiety $[9,34,35]$. On the other hand, smoking improves concentration, reaction time, and performance of certain tasks $[9,35,36]$.

Among the withdrawal symptoms that can occur we can cite irritability, depressed mood and restlessness [7]. The feeling that there is little pleasure in life, so called anhedonia, can also be found. with the withdrawal of nicotine, as it occurs with other drugs of abuse [37].

Therefore, the basis of nicotinic addition is a combination of positive reinforcements, including mood enhancement, and the attempt to attenuate or suppress withdrawal symptoms, known as negative reinforcement [2]. The use of didactic material and visual resources with all these concepts of addictive nicotine mechanisms was also very important as an aid in the motivation for the cessation of smoking, as highlights Bethea et al. (2015) [26].

To evaluate the impact of smoking on quality of life, standardized and validated instruments were used for our culture [19-24]. Two generic instruments were used to understand how smoking could be related to general aspects of human life, which were the questionnaires SF36 and the Fantastic Lifestyle. The specific QoL assessment instruments were used to evaluate anxiety (STAI $\mathrm{s} / \mathrm{t}$ ) and depression (SRQ-20). Studies point to anxiety and depression as trigger indicators for cigarette use and depression associated with difficulty in smoking cessation [25,38,39]. In general, people with a history of depression are twice as likely to smoke [25). Baiardini et al. (2014) concluded that successful smoking cessation was related to less symptoms of these mental disorders like anxiety and depression [38]. Zwar et al. (2014) demonstrated that tobacco dependence and cessation difficulties had been associated with higher mood disorder, anxiety, and depression disorders incidence [39]. In agreement with these findings, among our sample, six individuals presented scores suggestive of depression through the SRQ20 questionnaire.

In a study by Mitra et al. (2004), it was demonstrated that individuals who quit smoking showed a significant improvement in mean SF-36 scores overtime for health in general, including the domains of mental health, energy, and vitality [40]. Accordingly, Xue et al. (2017), who used SF36 as an instrument to evaluate patients with non-smokers coronary heart disease had a better health-related quality of life (HRQoL) than the smokers' group [41]. In our study, the evaluation after the smoking cessation treatment showed that the indicators of the LPA, SA, and EA domains had higher scores.

STAI $\mathrm{s} / \mathrm{t}$ are instruments capable of demonstrating that the participants were less anxious than they usually are at the time of application. In the first evaluation of the anxiety, it was verified that the values of STAI-s were smaller than the STAI-t. This fact may be associated with decreased anxiety at the beginning of the smoking treatment and may be interpreted as a perspective of change on the part of patients. However, the anxiety score as a trait was higher than the punctual anxiety, suggesting that a therapeutic work should be stimulated and/or offered for its reduction or control so that they can collaborate for the success of the treatment or at least for the reduction of the chances of it remaining a trigger for cigarette use. In the second evaluation of anxiety, he found that the values of STAI-s were higher than the STAI-t. These results suggest that at the time of application of the questionnaires, the participants were more anxious than usual and also may be associated with the large number of relapses that occurred in this sample. According to Watson et al. (2017), smokers with moderate to high levels of anxiety are at higher risk for cessation failure than those with low anxiety levels [42].

The assessment by the Fantastic Lifestyle instrument showed a "Fair" average (53 points) on the first evaluation indicating that there was a need for lifestyle changes in this group. The second evaluation showed the average score was compatible with the "Good" rating (55.67 points), which means a little improvement. However, we observed that the patients who had the worst results (lowest score) were the same ones who did not cease and/or relapsed, while the patients who completely stopped had the best results in the evaluation of the lifestyle. In a recent study, Xue et 
al. (2017), demonstrated that smokers who quit smoking after drug-eluting stents implantation showed comparable improvement health status and quality-of-life benefits when compared with nonsmokers and significantly better HRQoL than smokers who continued smoking [41]. However, in the aforementioned study, there was a compulsory need for post-infarction cessation, as opposed to the present study in which treatment was initiated voluntarily.

Studies have shown an association between smoking and depression [40,43,44,46]. Research has shown that not only the current depression observed more frequently among active smokers but also a history of depression or depressive symptoms has been associated with failure to quit smoking $[43,44]$. In fact, previous research suggests that anxiety and depression are more associated with smoking than depression alone $[45,46]$.

In our sample, the first evaluation by the SRQ-20 questionnaire showed that six participants (40\%) presented indicators compatible with depression. In the second application, we found a decreased number of participants with suggestive depression, while one had an increased questionnaire score.

Goldenberg et al. (2014) concluded that low QoL life and depression are associated with increased chances of smoking initiation and less chance of successful cessation [25]. On the other hand, Grabovac et al. (2017) analyzed how a smoking cessation intervention influenced changes in QoL and concluded that there were no significant differences in QoL in those who continued to smoke and those who discontinued treatment at follow-up. However, this study was done with patients with HIV infection, which is known as a disease that usually interferes with the quality of life [47].

Other studies have shown that successful cessation of smoking resulted in better QoL by using subjective methods of evaluation $[48,49]$. In the present study, in general, there were no significant changes in QoL before and after three months of treatment, but it was observed that patients who quit smoking and did not relapse obtained improvement in QoL indicators. Increased anxiety and depression may have contributed to cases of relapse and non-cessation, as it is directly related to their quality of life.

The major limitation of this study was the small number of the included participant. The lack of psychiatric evaluation and follow-up for patients with suggestive depression and anxiety disorder was another aspect that limited the probable prescription of anxiolytics and/or antidepressants which could contribute to increasing the smoking cessation success. Due to these pointed limitations, we believe that and further studies with a larger sample size should be recommended.

\section{CONCLUSIONS}

The smoking cessation treatment can be correlated with increased levels of anxiety and depression and unsuccessful outcomes to quit smoking. The improvement of the general quality of life can remain with continuous abstinence and be evaluated by QoL questionnaires. This quality of life improvement should be accessed as a new health outcome on intensive tobacco cessation.

\section{Acknowledgment}

This research was supported by grant \# 2016/08633-0 and \# 2016/12073-0, São Paulo Research Foundation (FAPESP), and University Extension grant (BEU), São Paulo State University (Unesp).

\section{Current Knowledge}

Tobacco use is an addictive and recurrent disease habitually associated with mental disorders like depression and anxiety. The high nicotine dependence can contribute to repeated failure quit attempts and persistent smoking habit. The tobacco use intensive intervention can enhance the odds of success and be a key action due to the general quality of life improvement. Despite this facts the QoL are not usually evaluated during the process of tobacco cessation treatment. 


\section{What This Paper Contributes To Our Knowledge}

The QoLs were used to evaluate health outcome on intensive tobacco cessation. The SRQ20 and STAI were related to relapse of smoking. The SF36 questionnaire indicated improvement in the domains of physical aspect limit, pain, social aspect, and emotional aspect. The tobacco cessation treatment provided improvement on Fantastic Lifestyle scores.

\section{REFERENCES}

1. World Health Organization. World health statistics 2017:monitoring health for the SDGs, Sustainable Development Goals [Internet]. Genebra: World Health Organization; 2017. Available at:http://apps.who.int/iris/bitstre am/10665/255336/1/9789241565486-eng.pdf?ua01[Accessed:2020 Sep 01].

2. Benowitz NL. Nicotine addiction. N Engl J Med. 2010 Jun 17;362(24):2295-303. doi: 10.1056/NEJMra0809890.PMID:20554984;PMCID:PMC2928221.

3. Brasil. Ministério da Saúde. Instituto Nacional do Câncer José de Alencar Gomes da Silva - INCA. Programa Nacional de Controle do Tabagismo [Internet];[acessed:2018 Jan 16]. Available at: http://www2.inca.gov.br/wps/ wcm/connect/acoes programas/site/home/nobrasi//programa-nacionalcontrole-tabagismo/tabagismoÄreferencias.

4. Lando HA, Hipple BJ, Muramoto M, Klein JD, Prokhorov AV, Ossip DJ, Winickoff JP. Tobacco is a global paediatric concern. Bull World Health Organ. 2010 Jan:88(1):2. doi:10.2471/BLT.09.069583. PMID:20428341;PMCID:PMC2802441.

5. Mikami I, Akechi T, Kugaya A, Okuyama T,Nakano T,Okamura H, Yamawaki S, Uchitomi Y. Screening for nicotine dependence among smoking-related cancer patients. Jpn J Cancer Res. 1999 Oct;90(10):1071-5. doi: 10.1111//.13497006.1999.tb00679.x. PMID: 10595734;PMCID:PMC5926006.

6. Knott V, Heenan A, Shah D, Bolton K, Fisher D, Villeneuve C. Electrophysiological evidence of nicotine's distracter-filtering properties in non-smokers. $J$ Psychopharmacol. 2011Feb;25(2):239-48. doi: 10.1177/0269881109348158. Epub 2009 Nov 25.PMID: 19939874.

7. Hughes JR, Hatsukami D. Signs and symptoms of tobacco withdrawal. Arch Gen Psychiatry. 1986 Mar;43(3):289-94. doi: 10.1001/ archpsyc.1986.01800030107013.PMID:3954551.

8. 2008 PHS Guideline Update Panel, Liaisons, and Staff. Treating tobacco use and dependence: 2008 update U.S. Public Health Service Clinical Practice Guideline executive summary. Respir Care. 2008 Sep;53(9):1217-22. PMID: 18807274.

9. Reichert J, Araújo AJ, Gonçalves CMC, Godoy I, Chatkin JM, Sales MPU, Santos SRRA. Smoking cessation guidelines. JBrasPneumol. 2008 0ct;34(10):84580. doi:10.1590/S1806-37132008001000014.

10. Agarwal R, Goldenberg M, Perry R, ISHak WW. The quality of life of adults with attention deficit hyperactivity disorder: a systematic review. Innov Clin Neurosci. 2012 May;9(5-6):10-21.PMID:22808445; PMCID:PMC3398685.
11. Johnson GK, Hill M. Cigarette smoking and the periodontal patient. J Periodontol. 2004 Feb;75(2):196-209. doi: 10.1902/jop.2004.75.2.196.PMID: 15068107.

12. Börnigen D, Ren B, Pickard R, Li J, Ozer E, Hartmann EM, Xiao W, Tickle T, Rider J,Gevers D, Franzosa EA, Davey ME, Gillison ML, Huttenhower C. Alterations in oral bacterial communities are associated with risk factors for oral and oropharyngeal cancer. Sci Rep. 2017 Dec 15;7(1):17686. doi: 10.1038/s41598-01717795-z.PMID:29247187;PMCID:PMC5732161.

13. Blot WJ,McLaughlin JK, Winn DM, Austin DF, Greenberg RS, Preston-Martin S, Bernstein L, Schoenberg JB, Stemhagen A, Fraumeni JF Jr. Smoking and drinking in relation to oral and pharyngeal cancer.Cancer Res. 1988 Jun 1;48(11):3282-7.PMID:3365707.

14. Gillison ML, Zhang Q, Jordan R, Xiao W, Westra WH, Trotti A, Spencer S, Harris $J$, Chung $\mathrm{CH}$, Ang KK. Tobacco smoking and increased risk of death and progression for patients with p16-positive and p16-negative oropharyngeal cancer. J Clin Oncol. 2012 Jun 10;30(17):2102-11. doi: 10.1200/JC0.2011.38.4099 Epub 2012 May 7.PMID:22565003;PMCID:PMC3397696.

15. Meneses-Gaya IC, Zuardi AW, Loureiro SR, Crippa JA. Psychometric properties of the Fagerström Test for Nicotine Dependence.J Jras Pneumol. 2009 Jan;35(1):73-82. English, Portuguese. doi: 10.1590/s1806-37132009000100011. PMID: 19219334

16. Fagerström K. Determinants of tobacco use and renaming the FTND to the Fagerstrom Test for Cigarette Dependence. Nicotine Tob Res. 2012 Jan;14(1):758. doi: 10.1093/ntr/ntr137.Epub 20110ct24.PMID:22025545.

17. DiClemente CC, Prochaska JO, Fairhurst SK, Velicer WF, Velasquez MM, Rossi JS. The process of smoking cessation: an analysis of precontemplation, contemplation, and preparation stages of change. J Consult Clin Psychol. 1991 Apr;59(2):295-304. doi:10.1037//0022-006x.59.2.295.PMID:2030191.

18. Campolina AG, Bortoluzzo AB, Ferraz M, Ciconelli RM. Validação da versão brasileira do questionário genérico de qualidade de vida short-form 6 dimensions (SF-6D Brasil). Cienc Saude Coletiva [online]. 2011;16(7):3103-10. doi: 10.1590/S1413-81232011000800010.

19. Añez CRR, Reis RS, Petrosk EL Versão Brasileira do Questionário "Estilo de VidaFantástico": Tradução e Validação para Adultos Jovens. Arq Bras Cardiol. 2008; 91(2):102-9. doi: org/101590/S1677-54492012000100007.

20. Mari JJ, Williams P.A validity study of a psychiatric screening questionnaire (SRQ-20) in primary care in the city of Sao Paulo. Br J Psychiatry. 1986 Jan;148:23-6. doi:PMID:3955316 DOl:10.1192/bjp.148.1.23.

21. Spielberger CD, Gorsuch RL, Lushene RD. STAl: manual for the State - Trait Anxiety Invetory. Palo Alto, CA: Consulting Psychologists Press; 1970.

22. Gorenstein C,Andrade L. Validation of a Portuguese version of the Beck Depression Inventory and the State-Trait Anxiety Inventory in Brazilian subjects. Braz J Med Biol Res. 1996 Apr;29(4):453-7.PMID: 8736107.

23. Andrade L, Gorenstein C, Vieira Filho AH, Tung TC, Artes R.Psychometric properties of the Portuguese version of the State-Trait Anxiety Inventory applied to college students: factor analysis and relation to the Beck Depression Inventory. Braz J Med Biol Res. 2001 Mar;34(3):367-74. doi:10.1590/s0100879x2001000300011.PMID: 11262588

24. Goldenberg M, Danovitch I, IsHak WW. Quality of life and smoking. Am J Addict. 2014 Nov-Dec;23(6):540-62. doi: 10.1111/.1521-0391.2014.12148.x. Epub 2014 Sep 25.PMID:25255868 
25. Bethea J, Murtagh B, Wallace SE. "I don't mind damaging my own body"a qualitative study of the factors that motivate smokers to quit. BMC Public Health. 2015 Jan 21;15:4. doi: 10.1186/1471-2458-15-4. PMID:25604029; PMCID: PMC4324408

26. Jhanjee S, Sethi H. The Fagerström test for nicotine dependence in an Indian sample of daily smokers with poly drug use. Nicotine Tob Res. 2010 Nov;12(11):1162-6. doi: 10.1093/ntr/ntq148. Epub2010 Sep 13.PMID:20837653.

27. Heatherton TF,Kozlowski LT,Frecker RC, Fagerström KO. The Fagerström Test for Nicotine Dependence: a revision of the Fagerström Tolerance Questionnaire. Br J Addict. 1991 Sep;86(9):1119-27. doi:10.1111/j.1360-0443.1991. tb01879.x. PMID: 1932883

28. Halty LS, Huttner MD, Oliveira Netto IC, Santos VA, Martins G. Análise da utilização do Questionário de Tolerância de Fagerström (QTF) como instrumento de medida da dependência nicotínica. JPneumologia. 2002;28(4):180-6. doi: 10.1590/S0102-35862002000400002

29. Dijkstra A, Tromp D. Is the FTND a measure of physical as well as psychological tobacco dependence? J Subst Abuse Treat.2002 Dec;23(4):367-74. doi: 10.1016/s0740-5472(02)00300-8.PMID:12495799.

30. Pietrobon RC, Barbisan JN, Manfroi WC. Utilização do Teste de Dependência à Nicotina de Fagerström como um instrumento de medida do Grau de Dependência. Rev HCPA. 2007;27(3):31-6.

31. Brasil. Ministério da Saúde. Secretaria de Vigilância em Saúde. Vigitel Brasil 2016: vigilância de fatores de risco e proteç̃o para doencas crônicas por inquérito telefônico [Internet]. Brasilia: Ministério da Saúde;2017. [accessed 2020 Sep 01]. Available at:http://portalarquivos.saude.gov.br/images/ pdf/2017/junho/07/vigitel_2016_jun17.pdf.

32. Silva LCC,Araújo AJ, Queiroz AMD, Sales MPU, Castellano MVCO. Controle do tabagismo: desafios e conquistas. J Bras Pneumol. 2016;42(4):290-8. doi: 10.1590/s1806-37562016000000145.

33. Baiardini I,Sorino C, DI Marco F,Facchini F.Smoking cessation, anxiety, mood and quality of life: reassuring evidences. Minerva Med. 20140ct;105(5 Suppl 1):15-21. Epub2014 Nov 14. PMID: 25396688.

34. Knott V, Heenan A, Shah D, Bolton K, Fisher D, Villeneuve C. Electrophysiological evidence of nicotine's distracter-filtering properties in non-smokers. J Psychopharmacol.2011Feb;25(2):239-48. doi:10.1177/0269881109348158. Epub 2009 Nov 25.PMID: 19939874

35. Dani JA, Heinemann S. Molecular and cellular aspects of nicotine abuse. Neuron. 1996 May;16(5):905-8. do::10.1016/s0896-6273(00)80112-9. PMID: 8630247.

36. Koob GF,Le Moal M. Drug abuse: hedonic homeostatic dysregulation. Science 19970ct3;278(5335):52-8. doi: 10.1126/science.278.5335.52. PMID: 9311926.

37. Zwar NA, Mendelsohn CP, Richmond RL Supporting smoking cessation. BMJ. 2014;348:f7535. doi: 10.1136/bmi.f7535.
38. Halladay JR, Vu M, Ripley-Moffitt C, Gupta SK, O'Meara C, Goldstein AO Patient perspectives on tobacco use treatment in primary care. Prev Chronic Dis. 2015Feb 5;12:E14. doi:10.5888/pcd12.140408.PMID:25654219;PMCID: PMC4318687.

39. Mitra M, Chung MC, Wilber N, Klein Walker D. Smoking status and quality of life: alongitudinal study among adults with disabilities. Am JPrev Med. 2004 Oct:27(3):258-60. doi:10.1016/.amepre.2004.06.002. PMID: 15450640.

40. Xue C, Bian L, Xie YS, Yin ZF, XuZJ, Chen QZ,ZZhang HL, Wang CQ. Impact of smoking on health-related quality of Life after percutaneous coronary intervention treated with drug-eluting stents: a longitudinal observational study. Health Qual Life Outcomes. 2017 Jan 3;15(1):1. doi: 10.1186/s12955-0160578-4.PMID:28069015;PMCID:PMC5220611.

41. Watson NL, Heffner JL, McClure JB, Mull KE, Bricker JB. Differential prevalence of established risk factors for poor cessation outcomes among smokers by level of social anxiety. Am J Addict. 2017 Mar;26(2):176-182. doi: 10.1111/ ajad.12509. Epub 2017 Feb 13.PMID:28191916; PMCID: PMC5328145.

42. Covey LS, Bomback A, Yan GW. History of depression and smoking cessation: a rejoinder. Nicotine Tob Res. 2006 Apr:8(2):315-9. doi: 10.1080/14622200500485250.PMID: 16766424

43. Killen JD, Fortmann SP, Schatzberg A, Hayward C, Varady A. Onset of major depression during treatment for nicotine dependence. Addict Behav. 2003 Apr;28(3):461-70. doi:10.1016/s0306-4603(01)00266-0.PMID: 12628619.

44. Mykletun A, Overland S, Aarø LE, Liabø HM, Stewart R. Smoking in relation to anxiety and depression: evidence from a large population survey: the HUNT study. Eur Psychiatry.2008 Mar;23(2):77-84. doi: 10.1016/j.eurpsy.2007.10.005 Epub 2007 Dec 21.PMID: 18082377

45. McCabe RE, Chudzik SM, Antony MM, Young L, Swinson RP,Zolvensky MJ Smoking behaviors across anxiety disorders. J Anxiety Disord. 2004;18(1):7-18. doi: 10.1016/j.janxdis.2003.07.003.PMID: 14725865.

46. Grabovac I,Brath H, Schalk H, Degen 0, Dorner TE. Clinical setting-based smoking cessation programme and the quality of life in people living with HIV in Austria and Germany. Qual Life Res. 2017 Sep;26(9):2387-2395. doi: 10.1007/ s11136-017-1580-y. Epub2017 Apr 20. PMID:28429240; PMCID: PMC5548958.

47. Hays JT,Croghan IT,Baker CL, Cappelleri JC, Bushmakin AG. Changes in health-related quality of life with smoking cessation treatment. Eur J Public Health. 2012 Apr;22(2):224-9. doi:10.1093/eurpub/ckq137. Epub 2010 Sep 30. PMID:20884658.

48. Piper ME, Kenford S, Fiore MC, Baker TB. Smoking cessation and quality of life: changes in life satisfaction over 3 years following a quit attempt. Ann Behav Med. 2012 Apr:43(2):262-70. doi:101007/s12160-011-9329-2.PMID:22160762; PMCID:PMC3298628

\section{Janete Dias Almeida} (Corresponding address)

Av Engenheiro Francisco José Longo Avenue, 777. São Dimas. São José dos Campos, São Paulo, Brasil. Zip code: 12245-000.

Date submitted: 2020 Mar 13

E-mail: janete.almeida@unesp.br
Accept submission: 2020 Apr 22 